\title{
Comments/Reflections
}

\section{Evidence of infanticide in the Cape mountain zebra (Equus zebra zebra)}

\author{
J.A. Britnell ${ }^{\mathrm{a}, \mathrm{b}, *, * *}$, L. $\operatorname{Vorster}^{\mathrm{c}}$ and S. Shultz ${ }^{\mathrm{a}, * * *}$ \\ ${ }^{a}$ School of Earth and Environmental Sciences, University of Manchester, Manchester M13 \\ 9NT, UK \\ ${ }^{\mathrm{b}}$ North of England Zoological Society (Chester Zoo), Caughall Road, Upton-by-Chester \\ $\mathrm{CH} 2$ 1LH, UK \\ ${ }^{c}$ Sanbona Wildlife Reserve, Barrydale 6720, South Africa \\ *Corresponding author's e-mail address: jake.britnell@ postgrad.manchester.ac.uk \\ ** ORCID: https://orcid.org/0000-0003-1527-7013 \\ *** ORCID: https://orcid.org/0000-0002-7135-4880
}

Received 11 December 2020; initial decision 10 May 2021; revised 9 June 2021; accepted 17 June 2021; published online 20 July 2021

\begin{abstract}
Infanticide has been described across mammal species. Infanticide is thought to be a tactic which increases reproductive opportunities or reduces competition over local resources. Species of the genus Equus exhibit life history traits such as expensive young, long gestation, lactation and dependency, extended inter-birth interval when there is a foal at foot and strong male reproductive skew. These traits suggest infanticide may be present throughout the genus. However, most documented cases of infanticide attempts come from captive populations and rely heavily on indirect accounts in free-roaming populations. Here, we report an infanticide attempt in Cape mountain zebra (Equus zebra zebra). The aggression was perpetrated by multiple bachelor males on two foals belonging to the same family group. The foals were separated from the parent group, chased and harried for a total of 45 minutes before the mothers and herd stallion were able to regain their offspring. We also report three cases of infanticide from necropsy. The injuries sustained by the foals are consistent with infanticide-based injuries documented in other equids species. The timing of these deaths occurs after a stallion turnover. These two cases provide the most conclusive evidence to date that infanticide takes place within mountain zebra.
\end{abstract}

\section{Keywords}

fitness, mortality, equids, aggression, sex ratio, social stability, stallion turnover, usurpation. 


\section{Introduction}

Infanticide is the act of killing a dependent offspring of the same species, often associated with species with extended parental care, resulting in an increase in access to either resources or reproductive opportunities for the perpetrator (van Schaik \& van Noordwijk, 2010). Multiple hypotheses exist to explain infanticidal behaviour (Table 1) (Hrdy, 1979; Ebensperger, 1998). Dependent on the life-history and ecological settings of the species, infanticide can be perpetrated by, and increase fitness of either sex. For males, it terminates maternal investment in unrelated offspring and can return females to reproductive status more quickly (Packer \& Pusey, 1982). Male infanticide should be prevalent in species with high competition between males for mating opportunities (Lukas \& Huchard, 2014). For females, infanticide of unrelated offspring can increase the availability of resources for their own offspring (Ebensperger, 1998). Female infanticide should be prevalent in species breeding in groups with intense bouts of reproductive output and large maternal energetic investment (Lukas \& Huchard, 2019). Many species experiencing infanticide develop counterstrategies to reduce risk such as stronger social bonds between females and more permanent male-female bonds (Van Schaik \& Kappeler, 1997; Opie et al., 2013). Finally, both male and female infanticide may be non-adaptive or perpetrated to predate offspring during times of resource limitation (Hrdy, 1979).

Although rare, infanticide has been described across mammals (Lukas \& Huchard, 2019). Equids have many life-history strategies which would suggest infanticide as an adaptive behaviour. Many equid species have high male skew in operational sex ratio (Ransom \& Kaczensky, 2016). Some species, including horses, plains and mountain zebra, have a social structure where a single male and multiple females form a single-male group. In this structure, breeding opportunities are monopolised by few males. Excess, non-breeding males and females without groups, especially juvenile females, often join bachelor groups (Joubert, 1972; Penzhorn, 1984). This social structure, with high variation in mating opportunities, increases the likelihood of infanticide (Lukas \& Huchard, 2014). The loss of a stallion male through death, defection or usurpation, may lead the new stallion male to commit infanticide. In plains zebra, stallion turnovers are frequent especially in groups with reproductive females (Vitet et al., 2021). Furthermore, females have long gestation periods, indicative of large maternal investment (Ransom \& Kaczensky, 2016). Equids also display behavioural traits which could serve 
Table 1.

Overview of the hypotheses to explain infanticidal behaviour.

\begin{tabular}{|c|c|c|c|}
\hline Hypothesis & Explanation & $\begin{array}{l}\text { Proposed adaptive } \\
\text { reason for behaviour }\end{array}$ & Associated behaviours \\
\hline $\begin{array}{l}\text { Predation/ } \\
\text { exploitation }\end{array}$ & $\begin{array}{l}\text { Infanticide as a } \\
\text { mechanism to obtain } \\
\text { food }\end{array}$ & $\begin{array}{l}\text { Increase food } \\
\text { availability }\end{array}$ & $\begin{array}{l}\text { Consumption of infant by } \\
\text { perpetrator. More frequent } \\
\text { in energy stressed } \\
\text { individuals and resource } \\
\text { poor areas }\end{array}$ \\
\hline $\begin{array}{l}\text { Resource } \\
\text { competition }\end{array}$ & $\begin{array}{l}\text { Infanticide as a } \\
\text { mechanism to obtain } \\
\text { increased resources } \\
\text { for perpetrator or its } \\
\text { offspring }\end{array}$ & $\begin{array}{l}\text { Increase resource } \\
\text { availability }\end{array}$ & $\begin{array}{l}\text { More likely in areas of } \\
\text { high density or poor food } \\
\text { availability }\end{array}$ \\
\hline $\begin{array}{l}\text { Adoption } \\
\text { avoidance }\end{array}$ & $\begin{array}{l}\text { Infanticide as a } \\
\text { mechanism to } \\
\text { ensure parental care } \\
\text { is provided to } \\
\text { related offspring }\end{array}$ & $\begin{array}{l}\text { Increase parental } \\
\text { certainty and } \\
\text { increase resources } \\
\text { and parental care to } \\
\text { related offspring }\end{array}$ & $\begin{array}{l}\text { Should be committed } \\
\text { more often by the sex that } \\
\text { bears the primary costs of } \\
\text { adoption. More likely to } \\
\text { occur after usurpation of } \\
\text { male in Single-male } \\
\text { groups }\end{array}$ \\
\hline $\begin{array}{l}\text { Sexual } \\
\quad \text { selection }\end{array}$ & $\begin{array}{l}\text { Infanticide as a } \\
\text { mechanism to } \\
\text { increase their } \\
\text { reproductive fitness }\end{array}$ & $\begin{array}{l}\text { Increase chance of } \\
\text { mating and siring } \\
\text { offspring or } \\
\text { decreases fitness of } \\
\text { competitors }\end{array}$ & $\begin{array}{l}\text { Infanticidal males should } \\
\text { not kill offspring they } \\
\text { have sired. The } \\
\text { elimination of offspring } \\
\text { should bring females into } \\
\text { reproductive status } \\
\text { quicker and infanticidal } \\
\text { males should be more } \\
\text { likely to sire subsequent } \\
\text { offspring }\end{array}$ \\
\hline $\begin{array}{l}\text { Social } \\
\text { pathology }\end{array}$ & $\begin{array}{l}\text { Behaviour is neutral } \\
\text { or pathological. } \\
\text { Infanticide occurs } \\
\text { due to accident, } \\
\text { disturbance or } \\
\text { general aggression }\end{array}$ & Non-adaptive & $\begin{array}{l}\text { Result of loss of habitat or } \\
\text { high-density areas }\end{array}$ \\
\hline
\end{tabular}

as counterstrategies to infanticide such as strong female sociality (Cameron et al., 2009), long-term male-female associations (Rubenstein, 1981), pregnancy blocks (Bartoš et al., 2021) and induced abortions (Berger, 1983). 
Within equids, infanticide is documented in feral and domestic horses (Equus caballus) (Duncan, 1982; Berger, 1983; Gray, 2009), plains zebra (Equus quagga) including most subspecies (Pluháček \& Bartoš, 2000, 2005; Pluháček et al., 2006), Hartmann's mountain zebra (Equus zebra hartmannae) in captivity (Joubert, 1972; Pluháček \& Bartoš, 2000) and Przewalski's horses (Equus ferus przewalskii) (Zharkikh, 1999; Chen et al., 2008; Feh \& Munkhtuya, 2008; Dorj \& Namkhai, 2013). However, apart from Equus ferus, infanticide has rarely been witnessed in studies of free-ranging wild equids with many accounts originating from captive populations. In plains zebra, a long-term study spanning 16 years in Hwange National Park, Zimbabwe, observed no infanticides (Vitet et al., 2021). Therefore, whether equid species commit infanticide in free-roaming conditions is questioned. Although, multiple videos are available on the internet or in documentaries regarding infanticide in zebra, the authors are unaware of any which involve Mountain zebra. Furthermore, although these videos provide anecdotal evidence, this is not incorporated into scientific literature.

Mountain zebra (Equus zebra) is a single-male band forming polygynous species, where a stallion monopolises breeding of multiple females (Penzhorn, 1984). At approximately one-year old, male offspring are displaced from their single-male bands and join a bachelor group (Penzhorn, 1984, 1985). These bachelor groups consist of non-band holding males and some juvenile females who are unlikely to have parentage of offspring found within single-male groups (Penzhorn, 1984, 1985). Male dominated bachelor groups are known to harass single-male groups. There has been no first-hand evidence of infanticide for the subspecies Cape mountain zebra (Equus zebra zebra, CMZ) or the species Mountain zebra (Equus zebra) in the wild. Despite this, male and female infanticide have been suggested in CMZ (Penzhorn, 1984; Lloyd \& Rasa, 1989). Penzhorn (1984) notes a previous "Nature Conservator" witnessing a fight between a female with a foal and a stallion when he "ventured too close" although he did not witness any aggression towards the foal first-hand. Penzhorn reports two herd stallions allegedly killing new-borns resulting in their removal from the reserve although Penzhorn did not witness the infanticide (Penzhorn, 1984). Multiple counterstrategies to infanticide have been suggested in Mountain zebra including pregnancy block (Penzhorn, 1985). Infanticide has also been suggested due to injuries thought to be from accidental aggression from the mother (Lloyd \& Rasa, 1989). 
HERE, we provide an eye-witness account of an infanticide attempt on two CMZ foals by a bachelor group in Mountain Zebra National Park. Furthermore, we provide evidence from necropsies of three foals in Sanbona Wildlife Reserve with injuries consistent with infanticide attempts documented in other equid species.

\section{Material and methods}

\subsection{Study areas and animals}

Mountain Zebra National Park (MZNP) $\left(32.1410^{\circ} \mathrm{S}, 25.5096^{\circ} \mathrm{E}\right)$ is a South African National Park in the Eastern Cape Province. MZNP is one of three relict populations and represents an important source used to restock CMZ into their historic range (Hrabar \& Kerley, 2013). Zebra in MZNP are unmanaged and subject to natural predation. MZNP has four biomes: Grassland, Nama Karoo, Thicket and Savannah. The population is approximately 1191 CMZ with a population density of 0.0558 individuals/ha (Lea et al., 2016). The infanticide attempt in MZNP was witnessed by Professor Susanne Shultz. The behaviour was recorded consistently from the onset of the event until the end of the incident.

Sanbona Wildlife Reserve (SWR) $\left(33.8663^{\circ} \mathrm{S}, 20.5284^{\circ} \mathrm{E}\right)$ is a 58000 ha privately-owned reserve within the Western Cape of South Africa. Population size is estimated to be $52 \mathrm{CMZ}$. CMZ were reintroduced to the area in 2016 with the first infant born in 2018 . The population is currently growing at an estimated rate of $20.9 \%$ per year. Adult sex ratio to date is approximately 50:50. During this study, CMZ in SWR could access supplementary feed. Some groups would regularly congregate near feeding sites. Feeding sites were positioned in areas central to known groups, minimizing competition between groups for the resource. Sites were mostly frequented by a single CMZ group such that inter-group competition for feeding sites is unlikely. Supplementary feeding sites were established following reintroduction due to extensive drought conditions in the area. Foals have been born to groups which were not known to use supplementary feed. The CMZ occupy a predator-free southern section of the reserve and therefore experience no predation pressure. SWR has two dominate biomes, fynbos and succulent karoo with population density of 0.0017 (individuals/ha). The cause of death of the three foals (SWR6, SWR7, SWR19) in SWR was investigated via necropsy performed by Dr Willem Burger, Veterinarian and Liesl Vorster, Ecologist. 


\subsection{Observational methods and definitions}

Observational sampling was performed systematically in SWR by Liesl Vorster. This sampling includes noting of group composition of all CMZ groups in SWR monthly. Zebra were observed in MZNP during population surveys between 2013-2020 by Professor Susanne Shultz, Neinke Alberts, Dr Jessica Lea and Jake Britnell. For each group encountered, we recorded time, GPS location, group composition and distance to other bands. Bands were defined as discrete units where individuals within the bands were closer to each other than to other bands. We used a gambit of group approach, whereby all associated individuals were considered group members. A group was deemed to be unstable if there was a change in individuals (excluding births, deaths or departure of juveniles) between observations. CMZ are thought to have groups which remain stable over the adult lifestage (Penzhorn, 1984).

\section{Results}

\subsection{Infanticide attempt}

During monitoring in MZNP on the 31st December 2012, we witnessed bachelor males harassing a single-male band with two young foals $(<3$ months old). The single-male group consisted of one stallion male, two adult females, two female sub-adults and two foals. At around 16:30 the singlemale band crossed a clearing and approached a perennial river to drink. Soon after, a band of 15 bachelor males approached the group, split and herded the foals from their group. All bachelors were in a very heightened state. The resident male and the two mothers attempted to regain their offspring by trying to separate the foals and drive them away from the bachelors. The resident male received significant and sustained aggression from bachelors and was driven away from the group. Bachelor males chased, bit at the foals and herded the foals away from the rest of the single-male group. All bachelor males were involved in the encounter, however, with the number of moving animals it was not possible to determine whether all males were involved with aggression towards the foals. In addition to chasing the foals, the bachelors also chased each other, engaged in rearing, lunging and biting. After approximately 20 minutes, one foal escaped the bachelors and returned to two female sub-adults who proceeded to move, with the foal, to a steep 
slope away from the bachelors. The chasing of the other foal continued. At 17:15, after 45 minutes of consistently herding, lunging at, and chasing the foal, the bachelor group broke into subgroups and the foal was able to return to the single-male group. The returning foal was rapidly ushered away by its mother and rejoined the rest of the single-male group. A single bachelor male continued to chase the single-male group. The foal was distressed and panting but showed no visible physical injury. At 17:25, the single-male group was approached again by two males from the bachelor group, but the stallion aggressively chased them away. The single-male-group stallion was vigilant towards bachelor males once the foals had returned, and the singlemale group moved off.

\subsection{Infanticide injuries from necropsy}

\subsubsection{Subject one and two - SWR6 and SWR19}

SWR6 was a female foal first seen on 10th January 2019. The foal was approximately four days old, was very lethargic and subsequently collapsed and died 10 minutes after observation began. A necropsy revealed exterior markings of a kick to the left side and exterior damage of bite marks to the ear (Figure 1). Bruising was found within the inside of the abdominal cavity associated with the position of the kick mark. The kick had resulted in broken ribs and a herniated piece of intestine through the abdominal cavity. No interaction was witnessed to know whether the perpetrator was male or female. SWR6 belonged to a group of 9 individuals composed of 6 adult females, 1 adult male, 1 female sub-adult and SWR6. The stallion had been with group since 2017 and SWR6 was likely his offspring.
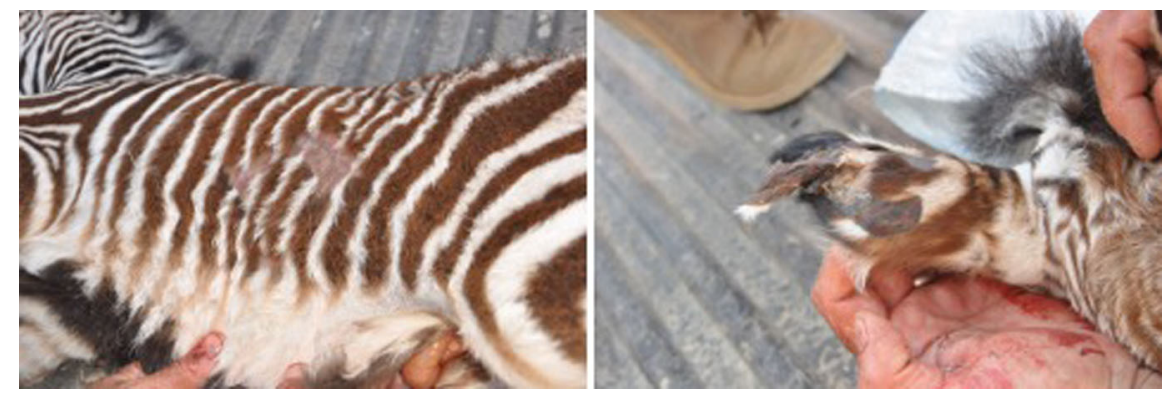

Figure 1. External injuries of the foal. left) displays two kick marks to the left-hand side of the animal which resulted in broken ribs. right) displays bite marks to the ear. 
SWR19 was a female foal born in July 2020. This two-day old foal was found dead with broken neck and ribs. SWR19 belonged to a group of 9 individuals, composed of 6 adult females and 1 male and 1 sub-adult female. Both SWR6 and SWR19 belonged to the same single-male group. The single-male group experienced a takeover in January 2020 (after the death of SWR6) and thus SWR19 was likely not the new male's offspring. The single-male group was known to use a feeding site, but no aggression was recorded between groups for access to the resource.

\subsubsection{Subject three $-S W R 7$}

SWR7 was first seen on 19th January 2019. The female foal was aged 3-4 days old. The foal was first seen lying down at 12:00 being guarded by the mother. The foal was later seen standing for a short period with its head pointed downwards and seemed unable to lift its head (Figure 2). The foal subsequently died and was retrieved on the 20th January 2019. A necropsy revealed the foal had sustained a broken neck and massive internal trauma with broken ribs. Four months prior to the birth of SWR7, the stallion was usurped by a new male. The foal was therefore unlikely to be the offspring of the new male. However, no interaction was witnessed to know whether a male or a female committed the attack. SWR7 belonged to a group of 7 individuals, composed of 5 females and 1 male and SWR7. The single-male group of SWR7 was known to use a supplementary feeding site, no other group is known to permanently use the area.

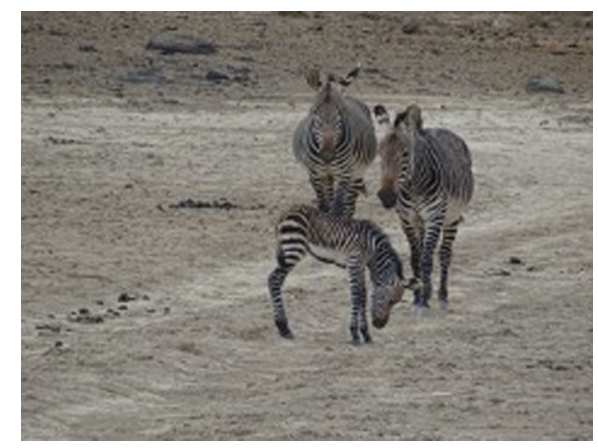

Figure 2. SWR7 at 15:30 where the foal was seen to be standing for a short period before falling down. Furthermore, the foal had sustained a broken neck, this was determined to be the reason the foal was unable to lift its head during observation. The individuals in the background are members of the breeding group. Photo taken by Liesl Vorster. 


\section{Discussion}

\subsection{Consistency of infanticide behaviour across equid species and potential explanations for behaviour}

\subsubsection{Infanticidal behaviour in MZNP}

We witnessed bachelor males harassing and aggressively attacking two foals, however, we did not witness direct injury. Behaviours are consistent with infanticidal attacks in other equids including chasing, isolating foals from group, lunging at and biting at foals. MZNP has a high density of CMZ but, due to high grass availability (Lea et al., 2016), intense resource competition is unlikely. As the aggressive display was perpetrated by a bachelor group, adoption avoidance is also unlikely as bachelors are unlikely to sire offspring. Exploitation is an unlikely explanation for a grazing species. Social pathology is a potential explanation as infanticide behaviour has been recorded in other species without successful male turnover (Watts, 1989), however, this explanation is usually implicated where animals are living in unnatural or stressful conditions. Therefore, sexual selection is the most likely cause of the behaviour we observed. Bachelor males increase their mating opportunities if they can successfully challenge, and displace, the resident stallion. In plains zebra, larger groups of females are more likely to experience a stallion turnover (Vitet et al., 2021). In feral horses, females are more likely to foal in a subsequent year if they have lost a foal (Cameron et al., 2003). Stallions have been shown to play an important role in protecting females from harassment by bachelor males (Linklater et al., 1999). This may explain the higher rates of foal-directed aggression in equids.

\subsubsection{Infanticidal behaviour in SWR}

Documented infanticide in other equids, in wild and captive conditions, describe biting focused to the legs, neck and head of the foal as well as kicks to the flanks and trampling while the foal is on the ground (Pluháček \& Bartoš, 2000; Gray, 2009), which was consistent with the injuries seen in SWR. From the five potential hypotheses, we can conclude predation/exploitation is unlikely. For SWR foals, resource competition, sexual selection, adoption avoidance and social pathology are all potential explanations. Infanticide at SWR may have been partially the result of congregation at supplementary feeding sites due to high resource competition and potentially higher general levels of contact between and within groups. All foals described were born to groups that accessed the supplementary feeding sites 
regularly. Within SWR, adoption avoidance is possible as stallion takeovers during pregnancy occurred in two of the three infanticides. Foals were killed within days of birth. In August 2020, another foal was born to the same single-male group as SWR6 and SWR19, this foal also died. The body was unable to be retrieved. Infanticide is a potential explanation. Importantly, groups in SWR may commit infanticide even when they do not use the feeding sites. A foal was born to a group of 6 individuals, 5 females and 1 male, which were not recorded to be using feeding sites. The group experienced a turnover of males three months prior to birth, the foal disappeared shortly after birth. As we did not witness infanticides take place in SWR, we cannot distinguish whether the perpetrator was the new stallion, a bachelor group or a group female. We also cannot distinguish whether the behaviour was purposive or accidental. However, due to the similarity of injuries seen in infanticide attempts in other equids, we would argue that these injuries were the result of infanticide.

\subsection{Implications for CMZ biology and management}

It is disputed whether infanticide plays an important role in the population dynamics of wild equids (Gray et al., 2012). Long term studies of wild plains zebra found no evidence that infanticides take place and foal survival was not impacted by stallion turnover (Vitet et al., 2021). However, in many free-ranging populations, it is extremely difficult to track foals unless intensive behavioural observations are conducted. Vitet and colleagues (2021) used hormone assays to detect non-pregnancy, mid-pregnancy and late pregnancy in mares to know whether a foal had been born even if it died before resighting or had been lost by abortion. Although they could not identify an explanatory variable for resighting rates in their dataset, they note that offspring survival from turnover was impacted when rates were assessed from mid-pregnancy onwards (Vitet et al., 2021). Infanticidal attacks may leave foals wounded and vulnerable to predation. If the aggressive action is not directly witnessed or predation occurs before the foal is found, infanticide may be underreported.

In many equid populations, foal mortality is high but the processes driving foal mortality are not well-documented (Grange et al., 2004). Within three years (2018-2020) in SWR, 5 of 24 foals (approx. 21\%) were found dead with infanticide consistent injuries. Although populations in this study did not have biased sex ratios, many CMZ populations with male-biased adult 
sex ratio are associated with low fertility and low population growth rates (Lea et al., 2018). Male-biased sex ratios could exacerbate competition for females, increase turnover events, increase the frequency and intensity of harassment from bachelor groups and increase the risk of male infanticide. We recommend investigation of behavioural differences and infanticide rates in these male-skewed populations and active management of operational sex ratios in at-risk populations such as translocation of excess males to other reserves.

\subsection{Conclusion}

Incidences of infanticide are rare across the animal kingdom; however, equids display multiple biological characteristics that suggest infanticide would be adaptive. We report an eye-witness account of an aggressive interaction, consistent with behaviours seen in infanticide attempts, between two CMZ foals and a band of bachelor males in MZNP. Furthermore, we document evidence from necropsies of three foals in SWR with injuries consistent with infanticide attempts in other equid species. These findings constitute the first first-hand record for the subspecies CMZ and the first record for the species in the wild. These provide the most direct and comprehensive evidence to date that infanticide takes place within the CMZ subspecies and within Mountain zebra in wild conditions.

\section{Acknowledgements}

The work of JAB on this project was funded by the Natural Environment Research Council (NERC) Doctoral Training Partnership (grant NE/ L002469/1). Necropsy were performed immediately by Veterinarian Dr Willem Burger with assistance from LV. JAB is also supported through the Chester Zoo Conservation Scholars programme. SS is funded by a Royal Society URF (UF110641). Author contributions: All authors conceived the manuscript; JAB wrote the initial draft of the manuscript. with contributions to the writing and editing from LV, SS. LV recorded group stability, population trends, assisted with three infanticide necropsies documenting and photographing the event. SS recorded the infanticide attempt at Mountain Zebra National Park. 


\section{References}

Bartoš, L., Dušek, A., Bartošová, J., Pluháček, J. \& Putman, R. (2021). How to escape male infanticide: mechanisms for avoiding or terminating pregnancy in mammals. - Mamm. Rev. 51: 143-153.

Berger, J. (1983). Induced abortion and social factors in wild horses. — Nature 303: 59-61.

Cameron, E.Z., Linklater, W.L., Stafford, K.J. \& Minot, E.O. (2003). Social grouping and maternal behaviour in feral horses (Equus caballus): the influence of males on maternal protectiveness. - Behav. Ecol. Sociobiol. 53: 92-101.

Cameron, E.Z., Setsaas, T.H. \& Linklater, W.L. (2009). Social bonds between unrelated females increase reproductive success in feral horses. - Proc. Natl. Acad. Sci. USA 106: 13850-13853.

Chen, J., Weng, Q., Chao, J., Hu, D. \& Taya, K. (2008). Reproduction and development of the released Przewalski's horses (Equus przewalskii) in Xinjiang, China. - J. Equine Sci. 19: 1-7.

Dorj, U. \& Namkhai, B. (2013). Reproduction and mortality of re-introduced Przewalski's horse. - J. Life Sci. 7: 623-629.

Duncan, P. (1982). Foal killing by stallions. - Appl. Anim. Ethol. 8: 567-570.

Ebensperger, L.A. (1998). Strategies and counterstrategies to infanticide in mammals. Biol. Rev. 73: 321-346.

Feh, C. \& Munkhtuya, B. (2008). Male infanticide and paternity analyses in a socially natural herd of Przewalski's horses: sexual selection? - Behav. Process. 78: 335-339.

Grange, S., Duncan, P., Gaillard, J.M., Sinclair, A.R.E., Gogan, P.J.P., Packer, C., Hofer, H. \& East, M. (2004). What limits the Serengeti zebra population? - Oecologia 140: 523-532.

Gray, M.E. (2009). An infanticide attempt by a free-roaming feral stallion (Equus caballus). - Biol. Lett. 5: 23-25.

Gray, M.E., Cameron, E.Z., Peacock, M.M., Thain, D.S. \& Kirchoff, V.S. (2012). Are low infidelity rates in feral horses due to infanticide? - Behav. Ecol. Sociobiol. 66: 529-537.

Hrabar, H. \& Kerley, G.I.H. (2013). Conservation goals for the Cape mountain zebra Equus zebra zebra - security in numbers? - Oryx 47: 403-409.

Hrdy, S.B. (1979). Infanticide among animals: a review, classification, and examination of the implications for the reproductive strategies of females. — Ethol. Sociobiol. 1: 13-40.

Joubert, E. (1972). The social organisation and associated behaviour in the Hartmann zebra Equus zebra hartmannae. - Madoqua 1: 17-56.

Lea, J.M.D., Kerley, G.I., Hrabar, H., Barry, T.J. \& Shultz, S. (2016). Recognition and management of ecological refugees: a case study of the Cape mountain zebra. - Biol. Conserv. 203: 207-215.

Lea, J.M.D., Walker, S.L., Kerley, G.I.H.I., Jackson, J., Matevich, S.C. \& Shultz, S. (2018). Non-invasive physiological markers demonstrate link between habitat quality, adult sex ratio and poor population growth rate in a vulnerable species, the Cape mountain zebra. Funct. Ecol. 32: 300-312.

Linklater, W.L., Cameron, E.Z., Minot, E.O. \& Stafford, K.J. (1999). Stallion harassment and the mating system of horses. - Anim. Behav. 58: 295-306. 
Lloyd, P.H. \& Rasa, O.A.E. (1989). Status, reproductive success and fitness in Cape mountain zebra (Equus zebra zebra). - Behav. Ecol. Sociobiol. 25: 411-420.

Lukas, D. \& Huchard, E. (2014). The evolution of infanticide by males in mammalian societies. - Science 346: 841-844.

Lukas, D. \& Huchard, E. (2019). The evolution of infanticide by females in mammals. Phil. Trans. Roy. Soc. B: Biol. Sci. 374: 20180075.

Opie, C., Atkinson, Q.D., Dunbar, R.I.M. \& Shultz, S. (2013). Male infanticide leads to social monogamy in primates. — Proc. Natl. Acad. Sci. USA 110: 13328-13332.

Packer, C. \& Pusey, A.E. (1982). Cooperation and competition within coalitions of male lions: kin selection or game theory? - Nature 296: 740-742.

Penzhorn, B.L. (1984). A long-term study of social organisation and behaviour of Cape mountain zebras Equus zebra zebra. —Z. Tierpsychol. 64: 97-146.

Penzhorn, B.L. (1985). Reproductive characteristics of a free-ranging population of Cape mountain zebra (Equus zebra zebra). - J. Reproduct. Fertil. 73: 51-57.

Pluháček, J. \& Bartoš, L. (2000). Male infanticide in captive plains zebra, Equus burchelli. Anim. Behav. 59: 689-694.

Pluháček, J., Bartoš, L. \& Čulík, L. (2006). High-ranking mares of captive plains zebra Equus burchelli have greater reproductive success than low-ranking ones. - Appl. Anim. Behav. Sci. 99: 315-329.

Ransom, J.I. \& Kaczensky, P. (2016). Behaviour of horses, zebras and asses. — In: Wild equids: ecology, management, and conservation (Ransom, J.I. \& Kaczensky, P., eds). John Hopkins University Press, Baltimore, MD, p. 33-34.

Rubenstein, D.I. (1981). Behavioural ecology of island feral horses. - Equine Vet. J. 13: 27-34.

Van Schaik, C.P. \& Kappeler, P.M. (1997). Infanticide risk and the evolution of male-female association in primates. — Proc. Roy. Soc. Lond. B: Biol. Sci. 264: 1687-1694.

Van Schaik, C.P. \& van Noordwijk, M.A. (2010). Infanticide. — In: Encyclopedia of animal behavior (Breed, M.D. \& Moore, J., eds). Elsevier, Oxford, p. 138-143.

Vitet, C., Duncan, P., Ganswindt, A., Mabika, C. \& Chamaillé-Jammes, S. (2021). Do infanticides occur in harem-forming equids? A test with long-term sociodemographic data in wild plains zebras. - Anim. Behav. 177: 9-18.

Watts, D.P. (1989). Infanticide in mountain gorillas: new cases and a reconsideration of the evidence. - Ethology 81: 1-18.

Zharkikh, T.L. (1999). The cases of infanticide in the Przewalski horses at Askania-Nova. Vestn. Zool. 80-82. 